\title{
Model Penentuan Jumlah Armada Angkutan Kota Yang Optimal Di Kota BANDUNG
}

\author{
${ }^{1}$ Aviasti, ${ }^{2}$ Asep Nana Rukmana, ${ }^{3}$ Jamaludin \\ ${ }_{1,2,3}$ Program Studi Teknik Industri Universitas Islam Bandung, Jl. Tamansari No. 1 Bandung 40116 \\ e-mail: ${ }^{1}$ Aviasti82@gmail.com
}

\begin{abstract}
Abstrak. Penelitian yang dilakukan adalah membuat model penentuan jumlah armada angkutan yang optimal di Kota Bandung, untuk mengatasi ketidakseimbangan antara jumlah armada yang tersedia dan jumlah penumpang yang membutuhkan. Jenis penelitian adalah kuantitatif dengan studi kasus dua trayek angkutan kota di Kota yaitu trayek Sadang Serang Caringin dan trayek Riung Bandung Dago yang pada saat penelitian awal dikategorikan tidak optimal. Untuk menentukan jumlah armada angkutan kota yang optimal, maka ada beberapa variabel yang terkait dengan hal ini diantaranya : jumlah penumpang terbanyak $(P)$, volumelfrekwensi armada $(F)$, kapasitas kendaraan $(C)$, waktu siklus (CTABA), load factor (LF),dan headway $(H)$. Hasil penelitian menunjukkan bahwa jumlah armada angkutan kota untuk trayek Dago - Riung Bandung dan Sadang Serang Caringin saat ini terlalu banyak tidak sesuai dengan kebutuhan artinya tidak optimal
\end{abstract}

Kata kunci: transportasi, angkutan kota, jumlah armada, optimal

\section{Pendahuluan}

Saat ini angkutan umum khususnya angkutan kota (angkot) di Kota Bandung memiliki jaringan pelayanan yang cukup luas hampir mencakup ke seluruh pelosok kota dengan sejumlah rute yang dilayani. Permasalahan angkutan kota (angkot) di kota Bandung masih belum tersesesaikan secara optimal, baik untuk kepentingan operator (pengusaha angkot), pengguna maupun pemkot dan instansi terkait lainnya. Kasus permasalah yang ada misalnya bagi operator : biaya operasional yang semakin tinggi dibanding dengan pendapatan yang dihasilkan, rebutan penumpang, dll.; bagi pengguna : ongkos yang cukup besar, banyak ngetem sehingga waktu tempuhnya lama, dll. Sedangkan bagi pihak pemerintah dan instansi terkait lainnya tetap dituntut harus mengatur dan mengendalikan sistem angkutan umum khususnya angkot yang dapat menguntungkan semua pihak terutama operator dan pengguna masyarakat kecil.

Indikasi penyebab permasalahan di atas diantaranya : tidak ada keseimbangan antara jumlah armada angkot dengan pengguna (banyak trayek yang kosong), dan rute trayek yang tumpang tindih (saling rebutan penumpang), sehingga efektifitas dan efisiensi sistem angkutan kota di kota Bandung cukup rendah. Hal ini berdampak pada kondisi operasional dan tingkat keoptimalan pelayanan angkutan kota yang rendah.

Berdasarkan teori transportasi diartikan sebagai usaha pemindahan atau pergerakan dari suatu lokasi ke lokasi yang lainnya dengan menggunakan suatu alat tertentu. Sedangkan sistem transportasi adalah suatu bentuk keterkaitan dan keterikatan antara penumpang, barang, sarana dan prasarana yang berinteraksi dalam rangka perpindahan orang atau barang yang tercakup dalam tatanan baik secara alami maupun buatan (Miro, 2005). Tujuan sistem transportasi adalah untuk mewujudkan penyelenggaraan pelayanan transportasi yang selamat, aman, cepat, lancar, tertib dan 
nyaman serta menunjang pemerataan pertumbuhan dan stabilitas, sebagai pendorong, penggerak dan penunjang pembangunan nasional serta mempererat hubungan antar bangsa (Warpani, 1990).

Secara umum permasalahan transportasi yang terjadi di perkotaan adalah masalah kemacetan lalu lintas serta pelayanan angkutan umum perkotaan. Pada saat ini sebagian besar pemakai angkutan umum masih mengalami beberapa aspek negatif sistem angkutan jalan raya (Tamin, 1997), yaitu:

- Tidak adanya jadwal yang tetap

- $\quad$ Pola rute yang memaksa terjadinya transfer

- Kelebihan penumpang pada saat jam sibuk

- Cara mengemudikan kendaraan yang sembarangan dan membahayakan keselamatan.

Sehingga untuk mengatasi permasalahan yang dihadapi diperlukan suatu pengaturan dan perencanaan kembali mengenai sistem angkutan kota khususnya di Kota Bandung yang tepat sesuai dengan perkembangan kondisi di lapangan. Penelitian ini berusaha menjawab salah satu permasalajan yang dihadapi yaitu: Bagaimana menentukan jumlah armada angkutan kota di Kota Bandung sesuai yang dibutuhkan dengan studi kasus dua trayek yaitu : Trayek Sadang Serang - Caringin dan Trayek Riung Bandung - Dago.

Tujuan utama dari penelitian ini adalah menghitung dan membuat suatu model untuk menentukan jumlah armada angkutan kota yang sesuai dengan kebutuhan. Dari tujuan utama di atas dapat diuraikan tujuan yang lebih spesifik adalah sebagai berikut :

1. Mengukur potensi pengguna angkutan kota untuk masing-masing trayek yang di studi.

2. Mengukur tingkat pengisian (okupasi) angkutan kota untuk masing-masing trayek yang di studi.

3. Menghitung jumlah armada angkutan kota yang diperlukan untuk masing-masing trayek yang di studi sesuai dengan kebutuhan.

\section{Penentuan Jumlah Armada Angkutan Kota Yang Optimal}

\subsection{Kependudukan Kota Bandung}

Kota Bandung tercatat sebagai daerah terpadat di Jawa Barat dengan jumlah penduduk 2.483.977 jiwa dengan laju pertumbuhan $1,16 \%$, sedangkan tingkat kepadatan penduduk mencapai rata-rata $14.847 \mathrm{jiwa} / \mathrm{Km} 2$. Penduduk usia produktif (15 - 64 tahun) sebesar 1.714.846 jiwa atau \pm 70,71\%. (Sumber : Kota Bandung Dalam Angka 2014).

Beberapa kecamatan dan tingkat kepadatan penduduk yang dilalui oleh rute trayek Dago - Riung Bandung dan trayek Sadang Serang - Caringin, dapat dilihat pada tabel 1 dan 2.

Tabel 1: Kecamatan dan Kepadatan Penduduk Rute Dago - Riung Bandung

\begin{tabular}{|c|l|c|}
\hline No. & \multicolumn{1}{|c|}{ Kecamatan } & Kepadatan Penduduk/Km2 \\
\hline 1 & Coblong & 17.690 \\
\hline 2 & Bandung Wetan & 9.076 \\
\hline 3 & Cibeunying Kidul & 20.299 \\
\hline
\end{tabular}




\begin{tabular}{|l|l|l|}
\hline 4 & Kiaracondong & 21.317 \\
\hline 5 & Batununggal & 23.766 \\
\hline 6 & Rancasari & 10.370 \\
\hline \multicolumn{2}{|c|}{ Rata-rata } & 17.086 \\
\hline
\end{tabular}

Tabel 2 : Kecamatan dan Kepadatan Penduduk Rute Sadang Serang - Caringin

\begin{tabular}{|c|l|c|}
\hline No. & \multicolumn{1}{|c|}{ Kecamatan } & Kepadatan Penduduk/Km2 \\
\hline 1 & Coblong & 17.690 \\
\hline 2 & Cibeunying Kaler & 15.580 \\
\hline 3 & Bandung Wetan & 9.076 \\
\hline 4 & Cicendo & 14.374 \\
\hline 5 & Bojong Kaler & 39.282 \\
\hline 6 & Andir & 25.993 \\
\hline 7 & Bandung Kulon & 21.793 \\
\hline \multicolumn{2}{|c|}{ Rata-rata } & 20.541 \\
\hline
\end{tabular}

\subsection{Waktu Antara (Headway)}

Pengukuran waktu antara (headway) kendaraan hanya dilakukan di dua tempat yaitu di masing-masing terminal dari kedua trayek angkot yang diteliti. Pengukuran headway yaitu dengan mencatat selang waktu keberangkatan kendaraan yang bergerak dari terminal asal maupun terminal tujuan. Dari hasil pengukuran, headway di setiap terminal rata-ratanya adalah sebagai berikut:

Tabel 3 : Headway rata-rata Trayek Dago - Riung Bandung

\begin{tabular}{|l|c|c|c|}
\hline \multirow{2}{*}{ Terminal } & \multicolumn{3}{|c|}{ Headway (Menit) } \\
\cline { 2 - 4 } & Pagi & Siang & Sore \\
\hline Dago & 2,5 & 3,5 & 3,5 \\
\hline Riung Bandung & 3,5 & 12,5 & 7,5 \\
\hline Rata-rata & 3,0 & 8,0 & 5,5 \\
\hline
\end{tabular}

Tabel 4 : Headway rata-rata Trayek Sadang Serang - Caringin

\begin{tabular}{|l|c|c|c|}
\hline \multirow{2}{*}{ Terminal } & \multicolumn{3}{|c|}{ Headway (Menit) } \\
\cline { 2 - 4 } & Pagi & Siang & Sore \\
\hline Sadang Serang & 3,0 & 10 & 7,5 \\
\hline Caringin & 3,5 & 7,5 & 5,0 \\
\hline Rata-rata & 3,25 & 8,75 & 6,25 \\
\hline
\end{tabular}

\subsection{Perhitungan Waktu Siklus}

Waktu siklus adalah waktu yang diperlukan armada dari terminal asal ke tujuan sampai balik lagi ke terminal asal, sedangkan pengukuran waktu tempuh terhadap kedua trayek angkutan kota ini masing-masing dilakukan selama dua minggu dengan jadwal 
pagi, siang dan sore. Untuk menghitung waktu siklus armada angkutan kota yaitu Waktu Tempuh + Deviasi + Waktu Henti di terminal atau dengan menggunakan rumus :

$$
\mathrm{CT}_{\mathrm{ABA}}=\left(\mathrm{T}_{\mathrm{AB}}+\mathrm{T}_{\mathrm{BA}}\right)+\left(\sigma_{\mathrm{AB}}+\sigma_{\mathrm{BA}}\right)+(\mathrm{TTA}+\mathrm{TTB}) \text {. }
$$

Dimana:

$\mathrm{CT}_{\mathrm{ABA}}=$ Waktu Siklus

$\mathrm{T}_{\mathrm{AB}} \quad=$ Waktu Tempuh dari A ke B

$\mathrm{T}_{\mathrm{BA}}=$ Waktu Tempuh dari B ke A

$\sigma_{\mathrm{AB}} \quad=$ Deviasi dari A ke B

$\sigma_{\mathrm{BA}}=$ Deviasi dari B ke A

$\mathrm{TT}_{\mathrm{A}}=$ Waktu Berhenti di A

$\mathrm{TT}_{\mathrm{B}}=$ Waktu Berhenti di B

Pada penelitian ini untuk Deviasi dan Waktu Berhenti diasumsikan masing-masing 5\% dan $10 \%$ dari Waktu Tempuh. Pada tabel 5 dan 6 diperlihatkan Waktu Siklus Trayek Dago - Riung Bandung dan Trayek Sadang Serang- Caringin.

Tabel 5. : Waktu Siklus (menit) Trayek Dago - Riung Bandung

\begin{tabular}{|c|c|c|c|c|c|c|c|c|}
\hline Hari & Jadwal & $\mathrm{T}_{\mathrm{AB}}$ & $\mathrm{T}_{\mathrm{BA}}$ & $\sigma_{\mathrm{AB}}$ & $\sigma_{\mathrm{BA}}$ & $\mathrm{TT}_{\mathrm{A}}$ & $\mathrm{TT}_{\mathrm{B}}$ & $\mathrm{CT}_{\mathrm{ABA}}$ \\
\hline \multirow{3}{*}{ Senin } & Pagi & 88 & 80 & 4.40 & 4.00 & 0.44 & 0.40 & 177.24 \\
\hline & Siang & 66 & 92 & 3.30 & 4.60 & 0.33 & 0.46 & 166.69 \\
\hline & Sore & 108 & 82 & 5.40 & 4.10 & 0.54 & 0.41 & 200.45 \\
\hline \multirow{3}{*}{ Selasa } & Pagi & 86 & 98 & 4.30 & 4.90 & 0.43 & 0.49 & 194.12 \\
\hline & Siang & 75 & 64 & 3.75 & 3.20 & 0.38 & 0.32 & 146.65 \\
\hline & Sore & 95 & 92 & 4.75 & 4.60 & 0.48 & 0.46 & 197.29 \\
\hline \multirow{3}{*}{ Rabu } & Pagi & 86 & 102 & 4.30 & 5.10 & 0.43 & 0.51 & 198.34 \\
\hline & Siang & 80 & 88 & 4.00 & 4.40 & 0.40 & 0.44 & 177.24 \\
\hline & Sore & 85 & 87 & 4.25 & 4.35 & 0.43 & 0.44 & 181.46 \\
\hline \multirow{3}{*}{ Kamis } & Pagi & 98 & 87 & 4.90 & 4.35 & 0.49 & 0.44 & 195.18 \\
\hline & Siang & 76 & 92 & 3.80 & 4.60 & 0.38 & 0.46 & 177.24 \\
\hline & Sore & 94 & 96 & 4.70 & 4.80 & 0.47 & 0.48 & 200.45 \\
\hline \multirow{3}{*}{ Jumat } & Pagi & 70 & 85 & 3.50 & 4.25 & 0.35 & 0.43 & 163.53 \\
\hline & Siang & 80 & 86 & 4.00 & 4.30 & 0.40 & 0.43 & 175.13 \\
\hline & Sore & 97 & 98 & 4.85 & 4.90 & 0.49 & 0.49 & 205.73 \\
\hline \multirow{3}{*}{ Sabtu } & Pagi & 74 & 70 & 3.70 & 3.50 & 0.37 & 0.35 & 151.92 \\
\hline & Siang & 77 & 80 & 3.85 & 4.00 & 0.39 & 0.40 & 165.64 \\
\hline & Sore & 85 & 95 & 4.25 & 4.75 & 0.43 & 0.48 & 189.90 \\
\hline \multirow{3}{*}{ Minggu } & Pagi & 98 & 68 & 4.90 & 3.40 & 0.49 & 0.34 & 175.13 \\
\hline & Siang & 75 & 74 & 3.75 & 3.70 & 0.38 & 0.37 & 157.20 \\
\hline & Sore & 75 & 76 & 3.75 & 3.80 & 0.38 & 0.38 & 159.31 \\
\hline
\end{tabular}


Tabel 6 : Waktu Siklus (menit) Trayek Sadang Serang - Caringin

\begin{tabular}{|c|c|c|c|c|c|c|c|c|}
\hline Hari & Jadwal & $\mathrm{T}_{\mathrm{AB}}$ & $\mathrm{T}_{\mathrm{BA}}$ & $\sigma_{\mathrm{AB}}$ & $\sigma_{\mathrm{BA}}$ & $\mathrm{TT}_{\mathrm{A}}$ & $\mathrm{TT}_{\mathrm{B}}$ & $\mathrm{CT}_{\mathrm{ABA}}$ \\
\hline \multirow{3}{*}{ Senin } & Pagi & 96 & 82 & 4.80 & 4.10 & 0.48 & 0.45 & 187.83 \\
\hline & Siang & 99 & 95 & 4.95 & 4.75 & 0.50 & 0.48 & 204.67 \\
\hline & Sore & 89 & 92 & 4.45 & 4.60 & 0.45 & 0.46 & 190.96 \\
\hline \multirow{3}{*}{ Selasa } & Pagi & 100 & 102 & 5.00 & 5.10 & 0.50 & 0.51 & 213.11 \\
\hline & Siang & 105 & 87 & 5.25 & 4.35 & 0.53 & 0.44 & 202.56 \\
\hline & Sore & 98 & 100 & 4.90 & 5.00 & 0.49 & 0.50 & 208.89 \\
\hline \multirow{3}{*}{ Rabu } & Pagi & 100 & 105 & 5.00 & 5.25 & 0.50 & 0.53 & 216.28 \\
\hline & $\mathrm{Si}$ & 102 & 90 & 5.10 & 4.50 & 0.51 & 0.45 & 202.56 \\
\hline & Sore & 98 & 95 & 4.90 & 4.75 & 0.49 & 0.48 & 203.62 \\
\hline \multirow{3}{*}{ Kamis } & Pagi & 105 & 95 & 5.25 & 4.75 & 0.53 & 0.48 & 211.00 \\
\hline & Siang & 102 & 94 & 5.10 & 4.70 & 0.51 & 0.47 & 206.78 \\
\hline & Sore & 102 & 96 & 5.10 & 4.80 & 0.51 & 0.48 & 208.89 \\
\hline \multirow{3}{*}{ Jumat } & & 94 & 87 & 4.70 & 4.35 & 0.47 & 0.44 & 190.96 \\
\hline & Siang & 92 & 96 & 4.60 & 4.80 & 0.46 & 0.48 & 198.34 \\
\hline & Sore & 95 & 95 & 4.75 & 4.75 & 0.48 & 0.48 & 200.45 \\
\hline \multirow{3}{*}{ Sabtu } & Pagi & 98 & 78 & 4.90 & 3.90 & 0.49 & 0.39 & 185.68 \\
\hline & Siang & 93 & 85 & 4.65 & 4.25 & 0.47 & 0.43 & 187.79 \\
\hline & Sore & 90 & 95 & 4.50 & 4.75 & 0.45 & 0.48 & 195.18 \\
\hline \multirow{3}{*}{ Minggu } & Pagi & 95 & 75 & 4.75 & 3.75 & 0.48 & 0.38 & 179.35 \\
\hline & Siang & 89 & 85 & 4.45 & 4.25 & 0.45 & 0.43 & 183.57 \\
\hline & Sore & 80 & 78 & 4.00 & 3.90 & 0.40 & 0.39 & 166.69 \\
\hline
\end{tabular}

\subsection{Perhitungan Jumlah Armada Optimal}

Untuk menentukan jumlah armada angkutan kota, maka ada beberapa variabel yang terkait dengan hal ini diantaranya : jumlah penumpang terbanyak $(\mathrm{P})$, volume/frekwensi armada $(\mathrm{F})$, kapasitas kendaraan $(\mathrm{C})$, waktu siklus $\left(\mathrm{CT}_{\mathrm{ABA}}\right)$, load factor (LF), dan headway (H).

- Data jumlah penumpang terbanyak (P) bisa didapat dari hasil survey lapangan secara langsung untuk angkutan yang naik - turun penumpangnya di terminal. Pada angkutan kota, data penumpang terbanyak sangat sulit jumlahnya untuk dipastikan dan membutuhkan waktu serta biaya yang cukup besar. Pendekatan yang dilakukan untuk hal ini adalah dengan menggunakan model formula :

$$
\boldsymbol{P}=\frac{\mathbf{6 0 . C .} \cdot \boldsymbol{F}_{\max }}{\boldsymbol{H}_{\text {pengamatan }}}
$$

Dimana:

$\mathrm{P} \quad=$ Jumlah penumpang per jam pada seksi terpadat

$\mathrm{C}=$ Kapasitas kendaraan

LF = Load Factor

$\mathrm{h} \quad=$ Headway aktual 
- Frekwensi armada adalah jumlah perjalanan kendaraan dalam satuan tertentu, untuk menghitung frekwensi ini menggunakan model formula :

$$
\boldsymbol{F}=\frac{P}{C . L F_{\text {desain }}}
$$

Dimana:

$$
\begin{array}{ll}
\mathrm{H} & =\text { Headway (menit) } \\
\mathrm{f} & =\text { Frekuensi } \\
\mathrm{C} & =\text { Kapasitas kendaraan } \\
\mathrm{P} & \text { = Jumlah penumpang per jam pada seksi terpadat } \\
\mathrm{LF} & =\text { Load factor design, diambil } 70 \% \text { pada kondisi dinamis }
\end{array}
$$

- Menghitung jumlah armada yang dibutuhkan (K), menggunakan model formula

$$
\begin{aligned}
& \boldsymbol{K}=\frac{\text { Waktu Siklus }_{\text {Headway }_{\text {hitung }}}=\frac{\boldsymbol{C T}_{A B A}}{\boldsymbol{H}_{\text {hitung }}}}{K=\frac{177,24}{2,22}=79,8 \approx 80 \text { kendaraan }}
\end{aligned}
$$

\begin{tabular}{|c|c|c|c|c|c|c|c|c|c|c|c|c|}
\hline Hari & Jadwal & W & $\mathrm{C}$ & $\begin{array}{c}\mathrm{Lf}_{\max } \\
(\%)\end{array}$ & $\begin{array}{l}\mathrm{LF}_{\mathrm{d}} \\
(\%)\end{array}$ & $\mathrm{CT}_{\mathrm{ABA}}$ & $\mathrm{H}_{\mathrm{p}}$ & P & $\mathrm{F}$ & $\mathrm{H}_{\text {hit }}$ & K & $\mathrm{K}^{\prime}$ \\
\hline \multirow{3}{*}{ Senin } & Pagi & 180 & 14 & 92.86 & 70 & 177.24 & 3.0 & 260 & 27 & 2.22 & 80 & 82 \\
\hline & Siang & 180 & 14 & 85.71 & 70 & 166.69 & 8.0 & 90 & 10 & 6.00 & 28 & 31 \\
\hline & Sore & 180 & 14 & 92.86 & 70 & 200.45 & 5.5 & 142 & 15 & 4.00 & 51 & 46 \\
\hline \multirow{3}{*}{ Selasa } & Pagi & 180 & 14 & 92.86 & 70 & 194.12 & 3.0 & 260 & 27 & 2.22 & 88 & 82 \\
\hline & Siang & 180 & 14 & 64.29 & 70 & 146.65 & 8.0 & 68 & 7 & 8.57 & 18 & 23 \\
\hline & Sore & 180 & 14 & 92.86 & 70 & 197.29 & 5.5 & 142 & 15 & 4.00 & 50 & 46 \\
\hline \multirow{3}{*}{ Rabu } & Pagi & 180 & 14 & 92.86 & 70 & 198.34 & 3.0 & 260 & 27 & 2.22 & 90 & 82 \\
\hline & Siang & 180 & 14 & 92.86 & 70 & 177.24 & 8.0 & 98 & 10 & 6.00 & 30 & 31 \\
\hline & Sore & 180 & 14 & 85.71 & 70 & 181.46 & 5.5 & 131 & 14 & 4.29 & 43 & 43 \\
\hline \multirow{3}{*}{ Kamis } & Pagi & 180 & 14 & 92.86 & 70 & 195.18 & 3.0 & 260 & 27 & 2.22 & 88 & 82 \\
\hline & Siang & 180 & 14 & 92.86 & 70 & 177.24 & 8.0 & 98 & 10 & 6.00 & 30 & 31 \\
\hline & Sore & 180 & 14 & 92.86 & 70 & 200.45 & 5.5 & 142 & 15 & 4.00 & 51 & 46 \\
\hline \multirow{3}{*}{ Jumat } & Pagi & 180 & 14 & 92.86 & 70 & 163.53 & 3.0 & 260 & 27 & 2.22 & 74 & 82 \\
\hline & Siang & 180 & 14 & 92.86 & 70 & 175.13 & 8.0 & 98 & 10 & 6.00 & 30 & 31 \\
\hline & Sore & 180 & 14 & 92.86 & 70 & 205.73 & 5.5 & 142 & 15 & 4.00 & 52 & 46 \\
\hline \multirow{3}{*}{ Sabtu } & Pagi & 180 & 14 & 92.86 & 70 & 151.92 & 3.0 & 260 & 27 & 2.22 & 69 & 82 \\
\hline & Siang & 180 & 14 & 78.57 & 70 & 165.64 & 8.0 & 83 & 9 & 6.67 & 25 & 28 \\
\hline & Sore & 180 & 14 & 78.57 & 70 & 189.90 & 5.5 & 120 & 13 & 4.62 & 42 & 40 \\
\hline \multirow{3}{*}{ Minggu } & Pagi & 180 & 14 & 71.43 & 70 & 175.13 & 3.0 & 200 & 21 & 2.86 & 62 & 64 \\
\hline & Siang & 180 & 14 & 64.29 & 70 & 157.20 & 8.0 & 68 & 7 & 8.57 & 19 & 22 \\
\hline & Sore & 180 & 14 & 71.43 & 70 & 159.31 & 5.5 & 110 & 12 & 5.00 & 32 & 37 \\
\hline
\end{tabular}

- Menghitung jumlah armada yang dibutuhkan pada jam sibuk (K'), menggunakan model formula :

$$
\begin{aligned}
K^{\prime} & =K \frac{W}{C T_{A B A}} \\
K^{\prime} & =80 \frac{180}{177,24} \approx 82 \text { kendaraan }
\end{aligned}
$$

Untuk menghitung jumlah armada selengkapnya dapat disajikan pada tabel berikut ini :

Tabel 7 : Jumlah Armada yang diperlukan Trayek Dago - Riung Bandung 
Tabel 8 : Jumlah Armada yang diperlukan Trayek Sadang Serang - Caringin

\begin{tabular}{|c|c|c|c|c|c|c|c|c|c|c|c|c|}
\hline Hari & Jadwal & W & $\mathrm{C}$ & $\begin{array}{c}\mathrm{Lf}_{\max } \\
(\%)\end{array}$ & $\begin{array}{l}\mathrm{LF}_{\mathrm{d}} \\
(\%) \\
\end{array}$ & $\mathrm{CT}_{\mathrm{ABA}}$ & $\mathrm{H}_{\mathrm{p}}$ & $P$ & $\mathrm{~F}$ & $\mathrm{H}_{\text {hit }}$ & $\mathrm{K}$ & $\mathrm{K}^{\prime}$ \\
\hline \multirow{3}{*}{ Senin } & 10 agt & 180 & 14 & 92.86 & 70 & 187.79 & 25 & 240 & 25 & 2.40 & 79 & 10 \\
\hline & & 180 & 14 & 92.86 & 70 & 204.67 & 75 & 90 & 10 & .00 & 35 & 31 \\
\hline & Sore & 180 & 14 & 92.86 & 70 & 190.96 & 6.25 & 125 & 13 & 4.62 & 42 & 40 \\
\hline \multirow{3}{*}{ Selasa } & Pagi & 180 & 14 & 92.86 & 70 & 213.11 & 3.25 & 240 & 25 & 2.40 & 89 & 76 \\
\hline & Siang & 180 & 14 & 92.86 & 70 & 202.56 & 8.75 & 90 & 10 & 6.00 & 34 & 31 \\
\hline & & 180 & 14 & 92.86 & 70 & 208.89 & 6.25 & 125 & 13 & .62 & 46 & 40 \\
\hline \multirow{3}{*}{ Rabu } & $\mathrm{P}$ & 180 & 14 & 92.86 & 70 & 216.28 & 3.25 & 240 & 25 & 2.40 & 91 & 76 \\
\hline & & 180 & 14 & 92.86 & 70 & & 8.75 & 90 & 10 & 6.00 & 34 & 31 \\
\hline & & & 14 & & 70 & & 6.25 & 116 & 12 & 00 & 41 & 37 \\
\hline \multirow{3}{*}{ Kamis } & gi & 1 & 14 & 92.86 & 70 & 0 & 3.25 & 240 & 25 & 2.40 & 88 & 76 \\
\hline & Siang & 180 & 14 & 92.86 & 70 & 206.78 & 8.75 & 90 & 10 & 6.00 & 35 & 31 \\
\hline & Sore & 180 & 14 & 92.86 & 70 & 208.89 & 6.25 & 125 & 13 & 4.62 & 46 & 40 \\
\hline \multirow{3}{*}{ Jumat } & Pagi & 180 & 14 & 92.86 & 70 & 190.96 & 3.25 & 240 & 25 & 2.40 & 80 & 76 \\
\hline & Siang & 180 & 14 & 92.86 & 70 & 198.34 & 8.75 & 90 & 10 & 6.00 & 34 & 31 \\
\hline & & 180 & 14 & 92.86 & 70 & 45 & 6.25 & 125 & 13 & 4.62 & 44 & 40 \\
\hline \multirow{3}{*}{ Sabtu } & & 180 & 14 & 71.43 & 70 & & 3.25 & 185 & 19 & 16 & 59 & 58 \\
\hline & & 180 & 14 & 92.86 & 70 & 187.79 & 8.75 & 90 & 10 & 6.00 & 32 & 31 \\
\hline & & 180 & 14 & 92.86 & 70 & 195.18 & 6.25 & 125 & 13 & 4.62 & 43 & 40 \\
\hline \multirow{3}{*}{ Minggu } & & 180 & 14 & 78.57 & 70 & 179.35 & 3.25 & 204 & 21 & 2.86 & 63 & 64 \\
\hline & Siang & 180 & 14 & 71.43 & 70 & 183.57 & 8.75 & 69 & 8 & 7.50 & 25 & 25 \\
\hline & Sore & 180 & 14 & 71.43 & 70 & 166.69 & 6.25 & 96 & 10 & 6.00 & 28 & 31 \\
\hline
\end{tabular}

\section{Kesimpulan dan Saran} disimpulkan :

Berdasarkan hasil pengumpulan data, pengolahan dan analisis, maka dapat

1. Jumlah armada angkutan kota untuk trayek Dago - Riung Bandung dan Sadang Serang - Caringin saat ini terlalu banyak tidak sesuai dengan kebutuhan artinya tidak optimal.

2. Berdasarkan hasil perhitungan jumlah armada yang diperlukan untuk kedua trayek tersebut adalah sbb :

a. Trayek Dago - Riung Bandung: Pagi $=82$ armada; Siang= 31 armada; Sore $=46$ armada.Jumlah armada saat ini 201 buah dan yang beroperasi tiap hari $150-170$ armada. Jadi terlalu banyak dan perlu dilakukan pengurangan karena tidak sesuai dengan kebutuhan.

b. Trayek Sadang Serang - Caringin: Pagi $=76$ armada; Siang $=31$ armada; Sore $=40$ armada. Jumlah armada saat ini 200 buah dan yang beroperasi rata-rata 160 armada, hal ini juga terlalu banyak dan perlu dilakukan pengurangan.

3. Model formula untuk menentukan jumlah armada yang optimal adalah :

$K=\frac{\text { Waktu Siklus }}{\text { Headway }_{\text {hitung }}}=\frac{C T_{A B A}}{H_{\text {hitung }}}$ 
180 | Aviasti, et al

$$
\boldsymbol{K}^{\prime}=K \frac{W}{C T_{A B A}}
$$

Saran yang dapat diajukan untuk penelitian ini adalah:

1. Perlu dilakukan kembali oleh pihak pemerintah dan instansi terkait lainnya mengenai pengaturan jumlah armada yang sesuai dengan kebutuhan, hal ini untuk mengatasi konflik rebutan penumpang di lapangan.

2. Hasil dari penelitian ini bisa dijadikan bahan awal untuk dilakukan kajian lebih lanjut yang komprehensif.

\section{Daftar pustaka}

Badan Pusat Statistik Kota Bandung. Kota Bandung Dalam Angka. Tersedia pada: http://bandungkota.bps.go.id/publikasi/kota-bandung-dalam-angka

Direktorat Jenderal Perhubungan Darat, 2002. Pedoman Teknis Penyelenggaraan Angkutan Umum di Wilayah Perkotaan dalam Trayek Tetap dan Teratur. Jakarta: Departemen Perhubungan RI.

Miro, Fidel, 2005. Perencanaan Transportasi Untuk Mahasiswa Perencana dan Praktisi. Jakarta: Penerbit Erlangga.

Tamin, Ofyar Z., 1995. Model Perencanaan Penentuan Rute Angkutan Umum Studi Kasus di Kota Badung. Tersedia pada: http://digilib.itb.ac.id/gdl.php?mod=browse \&op=read\&id=jbptitbpp-gdl-grey-1995-09ofyarzta $1845 \& q=\% 20$ Model $\% 20$

Perencanaan \%20Penentuan\%20Rute\%20Angkutan\%20Umum: 20Studi\%20Kasus\% 20di\%20Kota\%20Bandung

Tamin, Ofyar Z., 1997. Perencanaan \& Pemodelan Transportasi. Bandung: Penerbit ITB.

Warpani, Suwardjoko, 1990. Merencanakan Sistem Perangkutan. Bandung: Penerbit ITB. 